\title{
Physical Experiment Information System for Students Client Application
}

\author{
Xiang Teng \\ Basic Teaching and Research Institute, Bohai University, Jinzhou, 121013, China
}

\begin{abstract}
The traditional learning of physics experiment has the problems of tediousness and low efficiency. With the development and popularity of information technology, so in the light of the above problems, an information system for physics experiment had been designed for students to improve their learning efficiency. First, this paper introduced the requirement analysis of information system for physical experiment; then the key technologies were described, including .NET technology and database connection technology; finally, functions of software were given, and taking the function of experimental data entry and the function of online experimental report entry as an example to give a specific process when you use. The establishment of system is propitious to understand the experimental learning situation for leaders at all levels timely and comprehensively; at the same time, it lays the foundation for the information construction of physics experiment learning.
\end{abstract}

Keywords- information technology; physics experiment; information system; requirement analysis.

\section{INTRODUCTION}

The popularity of the campus network provides practical basic conditions for network teaching, and information system for physical experiment can be developed based on campus network to provide a good network support platform for teaching management and full open physics experiment [1]. Today is the information age, and all the technologies are high-speed developing regardless of areas, so every industry or field is inseparable from the support of computer. At present, the development of common experiment achieved the experiment teaching goals that the students' ability of teaching design, constructing and maintaining teaching system and management ability. But with the development of educational information, there are many problems in experimental teaching due to lack of support environment of information management: it cannot renews experimental teaching contents according to needs of the times; it is not able to release related notifications timely; there are too much experiment classes and less experiment teachers, so teachers are not accurate and comprehensive grasp students' information. To solve the above problems, it is urgent to establish an information management system of experimental teaching based on campus network. The software is designed to get the standardized, scientific, information management for physical experiment information, and it can improve the efficiency of teachers.

\section{REQUIREMENT ANALYSIS}

System analysis has become an indispensable software engineering activity in software engineering, which is connected with the system engineering and software system design. The basic task of system analysis is to accurate answer what function must exist in the system, what can be done, what kind of services can be provided [2]. Throughout the system design process, system requirement analysis is the most important step, which has a decisive role. A good first step is critical, and this directly determines the software's popularity.

Requirement analysis of system is divided into functional requirement and non-functional requirement. In accordance with the construction requirement and purpose of the experiment management system for colleges and universities, as well as combined with the inherent characteristics of the experimental management, there are two kinds of users involved in the system, including teachers and students. The functional requirements of each user will be analyzed according to role. Functional requirements of teachers: (1) managing students information: students information is generated by the super users, and the teachers mainly complete adding and deleting students information; (2) viewing students marks: including to query on all students marks; (3) rating for experiment: scoring for experimental operations and answer questions of all students; (4) the administrator added: the main function is to add and remove background administrators; (5) managing experiment information: it is responsible for renewing the experiment principles, experimental problems, experiment reports and others timely. Functional requirements of students: (1) entering experiment data: students can enter test data; (2) viewing experiment report: checking their own experiment reports; (3) viewing experiment principle: the experiment purpose, experiment principle, experiment content and discussion of basic experiment methods can be queried; (4) viewing results: students can view their own experiment results. Non-functional requirement refers to that the software product not only meets the specific requirements of users, but also it must have some non-specific requirements, including security, reliability, robustness, easy-to-use, maintainability and others [3]. 


\section{KeY TECHNOLOGY}

.NET integrates advanced concept of software architecture, which makes the Internet itself as a foundation for building next-generation operating system. And it extends the design ideas of Internet and operating system to allow developers to create device-independent applications. .NET includes five parts: .NET development platform, .NET server, .NET basic service, .NET terminal equipment and .NET user experience. Among them, .NET framework in .NET development platform is the core part of the .NET software structure, and the other four parts are integrated around .NET framework tightly. .NET framework provides the execution environment for Web services and general Windows applications. It integrates language development, code compilation, component configuration, program execution, and object interaction and other functions at all levels[4-6]. .NET reduces the burden on the programmers due to that programmer focuses on functions what he really wants without having to think too much extra stuff, thus the speed of development can be accelerated greatly.

Database connection, an expensive, critical, limited resource, is very important, which is particularly prominent in Web page accessed by multiple users. So the management for database connection can affect the performance of the entire application [7]. The basic idea of connection pool is to establish some connections in advance, which can be placed in memory object for future use. So when an application needs to establish a database connection, simply taking one from memory to use, rather than establishing a new connection. Similarly, the connection can be replaced to the memory after use. The establishment and disconnection of the connection are managed by connection pool. The execution efficiency of program will be greatly enhanced by using connection pool [8]. Database connection code is as follows:

\section{Sub ConnectionDatabase}

Dim ConnStr

ConnStr = "Provider = Sqloledb; User ID = a; Password =a; Initial Catalog = PhysicsExperiment; Data

Source =" \& SqlLocalName;

On Error Resume Next

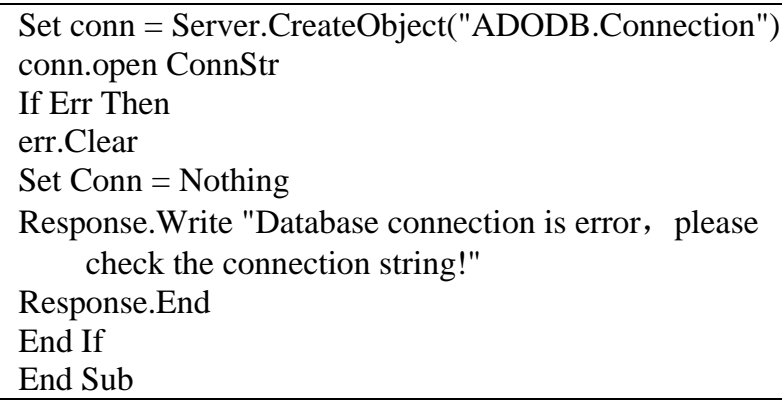

\section{SOFTWARE DESIGN}

Functional structure division of system follows principle of from top to bottom and module independence. According to this thinking, the functional requirement and non-functional requirement in requirement analysis was designed. The design of software mainly achieved the function of viewing experiment notification, the function of entering experiment data, the function of viewing experiment report, the function of viewing experiment principle and the function of viewing experiment results. Taking the function of entering experiment data and the function of online entering experiment report as an example to explain the process of various functions achievement.

The process of experiment data entry: first, students enter the landing page, and they need to log in to be able to carry out a series of operations. Entering your ID and password, the ID or password error will be prompted if you fail to log in and you will stay on the page to continue landing; if the landing is successful, you will enter into the page of experiment data entry. First, you need to fill in experiment date, name and instructor and other basic information in the top of the page; and then you can enter your own experiment data; finally clicking on the insert button, the inserted data will be displayed at the bottom of the page if you insert successfully; if the insert is unsuccessful, you will continue to stay on this page. The flow chart of experiment data entry shows in Fig. 1. 

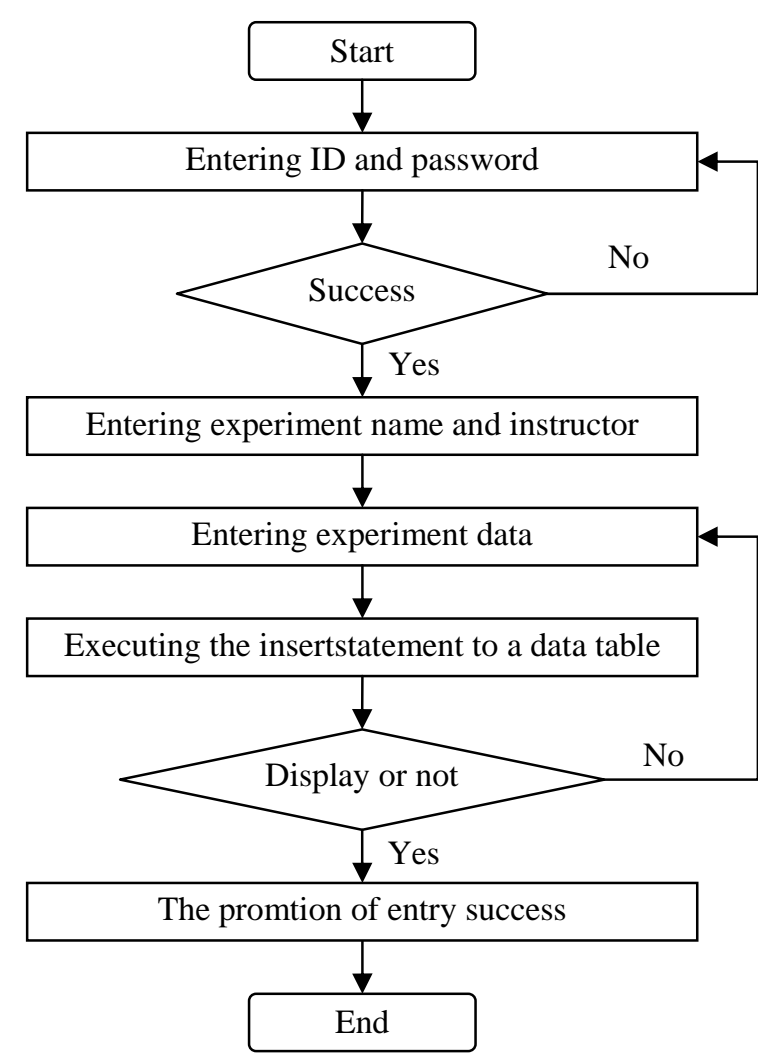

Figure 1.The flow chart of experiment data entry

The process of online experiment report entry: first you need to enter your ID and password in the landing page, the ID or password error will be prompted if you fail to log in and you will stay on the page to continue landing; if the landing is successful, you will enter into the page of experiment report entry. First, you need to fill in experiment number, experiment name and other basic information; and then entering the experiment process, such as experiment purpose, experiment principle and experiment procedure and others; finally, in order to avoid the phenomena of copying textbooks and others reports, the information you filled is needed to check repetition rate. The entry successful will be prompted if the repetition rate less than $30 \%$, otherwise entry is unsuccessful. And the overlaps will be displayed in red, so you need to re-enter. The flow chart of online experiment report entry shows in Fig. 2.

\section{V.CONCLUSIONS}

The continuous progress and the wide application of information technology provide the necessary conditions for information construction of experimental teaching. With the continuous advance of experimental teaching information, as well as the continuous enhance of the importance for research and practice, university experiment information system cannot be ignored as an important part of information construction of experiment

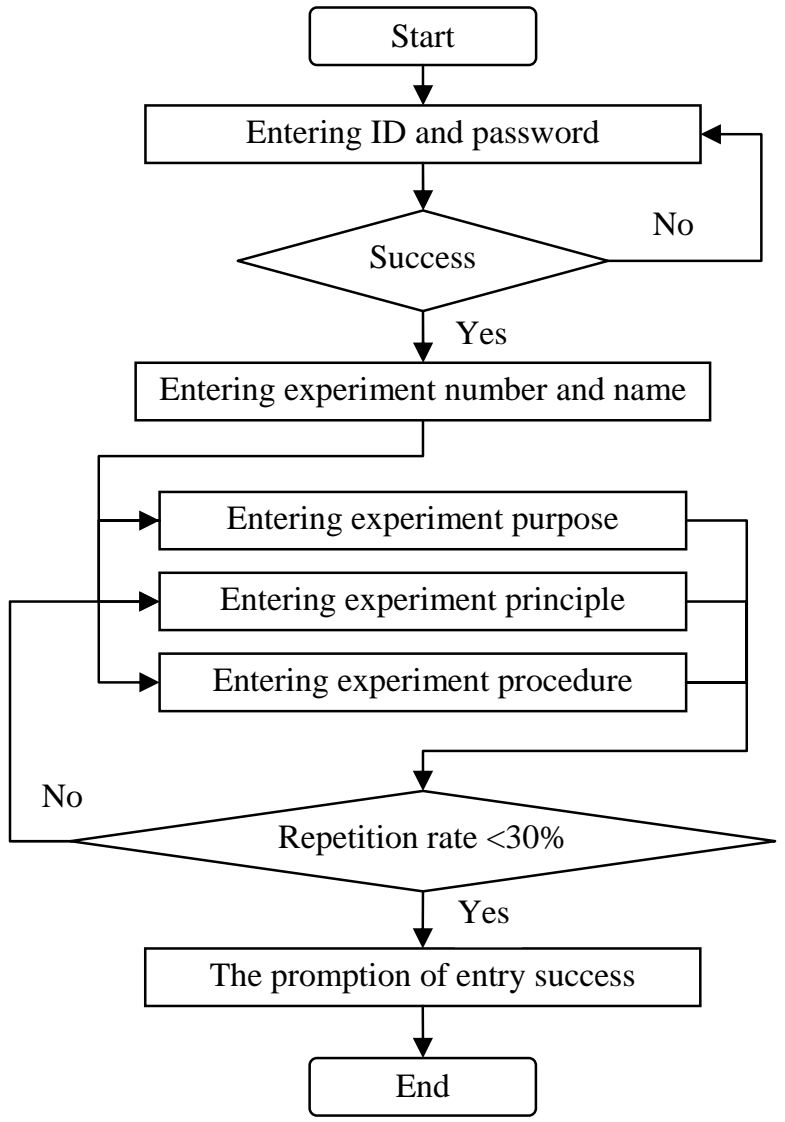

Figure 2. The flow chart of online experiment report entry teaching [9]. The student software of information system for physical experiment was designed in the light of the shortcomings of traditional experiment teaching. In summary, this paper starts with requirement analysis to introduce the key technologies and define the overall functions of the software. The software lays a good foundation and information platform for the infrastructure of experiment teaching and the improvement of teaching quality; the software can improve the degree of office automation and efficiency; and it is in line with the reform of the school's teaching and teaching institutions effectively [10].

\section{ACKNOWLEDGEMENTS}

The research work was supported by "Teaching Reform Project of Bohai University: Research and practice on modern physics virtual experiment simulation system of development.

\section{REFERENCES}

[1] J. Yan. The University Physics Experiment Administrative System for Design on Distributed Multi-tier Structure. Master's degree of Central China Normal University, 2007.

[2] M. Y. Shen. Design and Implementation of Experiment Management System in Jinhua Polytechnic. Master's degree of University of Electronic Science and Technology, 2012. 
[3] Baidu Encyclopedia, Non-functional Requirement. http://baike.baidu.com/link?url=SG3ssMlfdNc_dI6hR85uZCGDuo Z0BAfYsxQfgrSsAWshAmXOLGTN3XBZyIIyaBs9gvTgunw5y8AHPLTWR5Qa, 2014-10-9.

[4] H. L. Chen, N. Cui, S. L. Cui, et al. Design and Realization of University Competition Management System Based on .NET Platform. Computer Technology and Development, 23(1), pp. 173176, 2013.

[5] T. F. Li, Y. J. Lu, S. B. Du. Design and Implementation of Data Structure teaching Website Based on .NET. Computer Programming Skills \& Maintenance, 21(6), pp. 121-123, 2014.

[6] Y. X. Zhao, Y. B. Wu. Design of fast development framework based on.NET. Computer Knowledge and Technology, 10(13), pp. 29963000, 2014.
[7] G. R. Zhou. Design and Implementation of Experimental Teaching Management Information System. Master's degree of Jilin University, 2010.

[8] X. Z. Zhang, X. F. Wang. The Application of Database Connection and Optimization Technique in Rapid Design Information Based on .NET Environment. Tianjin Science \& Technology. 16(1), pp. 21-24, 2007.

[9] C. Li. Design and Development of University Experimental Management System Based on ASP.NET. Master's degree of Tianjin University, 2012.

[10] J. Wei. Design and Implementation of Physics Experiment Teaching Management System. China Computer \& Communication, 4(4), pp. 56-57, 2010. 